\title{
IMPLICAÇÕES DO PROCESSO DE FABRICAÇÃO DO COMPÓSITO PLÁSTICO REFORÇADO COM FIBRA DE VIDRO SOBRE O MEIO AMBIENTE E A SAÚDE DO TRABALHADOR: O CASO DA INDÚSTRIA AUTOMOBILÍSTICA
}

\author{
IMPACTS OF THE MANUFACTURING PROCESS USING FIBERGLASS \\ REINFORCED PLASTIC COMPOSITE ON THE ENVIRONMENT AND \\ OCCUPATIONAL HEALTH: THE AUTOMOTIVE INDUSTRY CASE
}

\author{
Cíntia Madureira Orth* cintia.orth@hotmail.com. \\ Nelma Baldin* nelmabaldin@univille.br \\ Cladir Teresinha Zanotelli** cladir.teresinha@hotmail.com \\ * Universidade da Região de Joinville (UNIVILLE) \\ ** Universidade Federal do Mato Grosso (UFMT)
}

Resumo: A produção de compósitos de plástico reforçado com fibra de vidro (PRFV) pode implicar em sérios danos à saúde do trabalhador e/ou ao meio ambiente devido, principalmente, à geração de aparas de processo e às emissões sonoras e atmosféricas. Neste sentido, este artigo teve como objetivo estudar as principais implicações do processo de Moldagem e Acabamento em PRFV em uma indústria automobilística sobre o meio ambiente e a saúde do trabalhador. Constatou-se que a moldagem aberta, processo adotado pela fábrica estudada, é a principal responsável pela geração de resíduos e que a perda de matérias-primas na forma de aparas pode chegar a 30\%. Essas aparas, que representam $45 \%$ de todos os resíduos gerados pela fábrica, têm como destino final o aterro industrial. Constatou-se, ainda, que devido ao uso de moldes abertos os níveis de estireno e de "pó de fibra" se encontravam acima dos limites de tolerância representando riscos à saúde do trabalhador. Sendo assim, não apenas a empresa estudada como também outras em situações semelhantes precisam considerar a possibilidade da adoção de tecnologias menos agressivas, como aquelas que usam moldes fechados. A redução dos impactos negativos dos processos produtivos em sua fonte geradora precisa fazer parte da política das empresas. A prevenção deve ser contínua e melhorada a cada dia.

Palavras-chave: Resíduos industriais. Saúde do trabalhador. Plástico Reforçado com Fibra de Vidro. Indústria automobilística.

\begin{abstract}
The production of fiberglass reinforced plastic composite parts may cause serious damages to the health of workers and/or the environment, especially due to the generation of process trimmings, noise level and gas emission. In view of that, this essay aims at assessing the main impacts of the Molding and Finish processes of an automotive plant on the environment and occupational health. It was observed that the open molding method adopted by the studied plant is the main cause of the generation of residues and that the waste of raw materials as trimmings may reach up to $30 \%$. The final destination of those trimmings, which represent $45 \%$ of all the residues generated by the factory, is the industrial landfill. It was also observed that, due to the use of open molds, the levels of styrene and fiber dust were above the tolerance limits, presenting risks to the health of the workers. Therefore, the studied company should consider the possibility of adopting less aggressive technologies, such as that used in closed molds. The reduction of the negative impacts of the productive processes in their source should be part of the company's policy. Furthermore, the prevention must be continuous and improved every day.
\end{abstract}

Keywords: Industrial residues. Occupational health. Fiberglass Reinforced Plastic. Automotive Industry. 


\section{INTRODUÇÃO}

O plástico faz parte da vida de milhões de pessoas e sua utilização crescente vem fazendo deste um produto essencial à vida moderna. Destaca-se que os primeiros plásticos que surgiram eram frágeis e quebradiços. Para suprir tais deficiências, uma das medidas tomadas foi o acréscimo de aditivos químicos e/ou fibras de vidro na composição de alguns materiais plásticos, tornando-os mais resistentes a choques, tração e flexão (GARCIA, 2009). A mistura de um reforço (fibra de vidro) a uma matriz polimérica (resina poliéster ou outro tipo de resina) e a uma substância catalisadora de polimerização forma o compósito denominado Plástico Reforçado com Fibra de Vidro (PRFV), cuja técnica permite a produção de peças com uma grande variedade de formatos e tamanhos: piscinas; caixas d'água; cascos e hélices de barcos; carroçarias de veículos e outras.

Os processos de produção de PRFV podem ser agrupados em moldagem aberta ou moldagem fechada. Na moldagem aberta (spray-up e hand lay-up), apenas uma das faces da peça fica em contato com o molde. Já os processos com moldes fechados (Resin Transfer Molding - RTM, Sheet Molding Compound - SMC e Bulk Molding Compound - BMC) utilizam dois moldes - macho e fêmea (PINTO, 2002). O spray-up ou moldagem à pistola é o processo de fabricação de compósitos mais usado no mundo, mesmo em regiões altamente industrializadas. Dentre as razões para essa popularidade está o fato da moldagem aberta ser um processo de fácil aplicação, não requerer altos investimentos e nem conhecimentos técnicos aprofundados (JACOB, 2002). ${ }^{1}$

Entretanto, a moldagem aberta é mais agressiva que processos que utilizam moldes fechados. No que se refere à questão ambiental, por conta da nãodegradabilidade natural da maioria dos PRFV e da redução crescente dos estoques naturais de matérias-primas, esses materiais têm sido responsáveis por sérios problemas ambientais, uma vez que o petróleo ainda constitui a principal fonte de matéria-prima para a fabricação desses plásticos. Outro agravante está na geração de resíduos durante o processo de laminação de um PRFV. A indústria de compósitos no Brasil gera cerca de 13 mil toneladas de resíduos por ano, entre aparas e rebarbas de processos e peças com defeito. A maior parte desses resíduos

\footnotetext{
${ }^{1} \mathrm{O}$ artigo "Spray-up offers process improvements" de Amanda Jacob (2002) recebeu tradução livre das Autoras deste artigo.
} 
tem como destino final os aterros industriais, sendo que as montadores de veículos, um dos principais segmentos consumidores de materiais compósitos, são tidas como grandes contribuintes para essa expressiva quantidade de resíduos (LIMA, 2010). Outra questão a ser considerada refere-se à complexidade da reciclagem do PRFV. A infusibilidade da resina empregada como matriz dificulta o seu reprocessamento, ou seja, o PRFV não pode ser derretido e remodelado como a maioria dos plásticos. Embora suporte alta temperatura, sofre carbonização, sem derreter, quando exageradamente aquecido (CANTO, 1997).

Além dos problemas ambientais, o processo de fabricação de compósitos em PRFV pode causar sérios danos à saúde do trabalhador. Um dos principais riscos diz respeito ao "pó de fibra" resultante do manuseio, mas, principalmente, do corte da própria fibra ou do compósito. Esse "pó" pode causar irritações respiratórias e quando em contato com a pele ou com os olhos, pode causar irritações temporárias. Além disso, destaca-se que cerca de $80 \%$ das dermatoses ocupacionais são produzidas por agentes químicos, dentre eles, solventes e resinas, materiais amplamente utilizados pela indústria de compósitos (SAMPAIO; RIVITTI, 2001; ALI, 2003 apud BERTINATO, 2007).

Outro problema relacionado à laminação de PRFV refere-se às emissões de estireno durante o processo de fabricação. O estireno e alguns produtos fabricados a partir dele, dentre eles a resina poliéster usada na laminação dos PRFV, são muito voláteis e liberam vapores tóxicos prejudiciais à saúde. As vias de entrada no organismo podem ser: inalação, olhos e pele. Na pele, pode causar irritações futuras. Se inalado, a superexposição pode causar irritação do sistema respiratório e outras membranas mucosas. Quando em contato com os olhos, pode causar irritação moderada, incluindo sensação de queima, lágrimas, vermelhidão ou inchaço. A exposição repetida ou prolongada ao estireno pode causar, ainda, náuseas, perda de apetite, depressão do Sistema Nervoso Central e debilidade geral.

Em vista dessas questões, o objetivo que motivou a elaboração do presente artigo foi o de estudar as principais implicações do processo de Moldagem e Acabamento em PRFV em uma indústria automobilística sobre o meio ambiente e a saúde do trabalhador. 


\section{METODOLOGIA}

A pesquisa foi desenvolvida por meio de um estudo observacional aplicado numa abordagem qualitativa e quantitativa. Foi executada em uma indústria que fabrica carrocerias para ônibus e tem sede na cidade de Joinville-SC, Brasil. O processo analisado, Moldagem e Acabamento em PRFV, abrange duas linhas de produção: tetos, fabricados em 4 modelos (Rodoviário, Urbano, Panorâmico Dobledeck e Micro-ônibus) e entre-janelas (modelo único). A coleta dos dados ocorreu de janeiro a maio de 2009. O período analisado foi de maio de 2008 a abril de 2009.

\subsection{Coleta de dados e procedimentos metodológicos}

O estudo ocorreu por meio de consultas aos arquivos da empresa, medições, estimativas, observações in loco e registros fotográficos. Foram analisadas as principais implicações da geração das aparas de $\mathrm{PRFV}^{2}$ e das emissões sonoras e atmosféricas.

Para o cálculo da quantidade de aparas de PRFV geradas mensalmente pela unidade fabril, primeiramente, levantou-se dados da produção mensal no período analisado, discriminando a quantidade de peças moldadas (QPM) e a quantidade de peças acabadas (QPA) de cada um dos cinco modelos de peças fabricadas. Após essa fase, pesquisou-se a quantidade de matéria-prima necessária para moldar cada um desses modelos (QMPP). As matérias-primas consideradas neste estudo foram: gel; resina; talco e fibras de vidro em geral. Os dados (QPM, QPA e QMPP) foram coletados junto aos arquivos do setor de Planejamento e Controle de Produção e Materiais da empresa. A quantidade de matéria-prima usada mensalmente foi obtida mediante a Equação 1 aplicada, separadamente, a cada um dos cinco modelos de peças (quatro tetos e uma entre-janela):

$$
\text { MPU = QPM } \times \text { QMPP }
$$

\footnotetext{
${ }^{2}$ As aparas de PRFV, comumente conhecidas como "aparas de fibra de vidro", correspondem ao material lançado, pela pistola, contra o piso, as paredes, as regiões não laminadas do molde e qualquer outra região/objeto do setor que não seja a área laminada. Neste estudo, incluem: os plásticos e os papelões impregnados com fibras e resina e os excedentes (rebarbas) cortados nas laterais e vãos dos moldes.
} 
Onde,

MPU $(\mathrm{kg})$ = quantidade de matéria-prima usada no mês.

QPM (un) = quantidade de peças moldadas no mês.

QMPP $(\mathrm{kg})$ = quantidade de matéria-prima por peça.

Em seguida, para determinar a quantidade total de aparas livres de contaminação nas duas linhas de produção, procedeu-se às pesagens das aparas geradas por cada um dos modelos. Para tanto, foram entregues aos trabalhadores responsáveis, várias planilhas de pesagem $(\mathrm{kg})$. As pesagens ocorreram em dois pontos da Moldagem e um ponto do Acabamento e durante um mês de produção

- ponto 1 (teto) - laminação: todo o papelão usado para proteger o piso e as paredes da laminadora foi pesado antes (peso inicial) e depois (peso final) da laminação de cada peça. A diferença entre o peso inicial e o peso final correspondeu à quantidade de aparas geradas por um único teto neste ponto. Após as pesagens, calculou-se a quantidade média (kg) de aparas geradas para laminar um único teto, independentemente do modelo que estava sendo laminado, uma vez que a área que recebe as aparas é a mesma para os quatro modelos de tetos produzidos;

- ponto 2 (teto e entre-janela) - desmoldagem: as rebarbas das laterais maiores dos tetos e todas as rebarbas das entre-janelas, depois de removidas, foram pesadas para determinar a quantidade média $(\mathrm{kg}) \mathrm{de}$ aparas geradas por cada um dos cinco modelos (4 tetos e 1 entre-janela) de peças em PRFV produzidas pela unidade;

- ponto 3 (teto) - acabamento: neste ponto, as rebarbas cortadas das laterais menores dos tetos foram pesadas para a determinação da quantidade média $(\mathrm{kg})$ de aparas geradas por cada um dos quatro modelos de tetos produzidos.

A somatória das quantidades médias de aparas geradas, por cada modelo, nos pontos 1 e 2 correspondeu à quantidade de aparas geradas na MOLDAGEM (APM). O ponto 3 , em si, correspondeu à quantidade média de aparas geradas no ACABAMENTO (APA). Destaca-se que, para auxiliar, organizar e facilitar a 
quantificação dos dados, várias planilhas foram elaboradas e usadas em todas as etapas que envolveram cálculos, tanto a anterior quanto as que se seguem.

Após determinada a quantidade de aparas geradas por cada um dos modelos de peças, a quantidade mensal dessas aparas, em cada linha de produção, foi obtida com o auxílio das Equações (2) e (3) aplicadas aos cinco modelos de peças fabricadas em todos os meses estudados. Para a determinação da quantidade total de aparas geradas no teto, fez-se a somatória de todas as QAGM (quantidade de aparas geradas na moldagem) e QAGA (quantidade de aparas geradas no acabamento) dos quatro modelos de tetos em cada um dos meses analisados.

QAGM = QPM $\times$ APM

QAGA = QPA $\times$ APA

Onde,

QAGM $(\mathrm{kg})$ = quantidade de aparas geradas na moldagem.

QPM (un) = quantidade de peças moldadas.

APM $(\mathrm{kg})$ = quantidade média de aparas geradas na moldagem de uma única peça.

QAGA $(\mathrm{kg})$ = quantidade de aparas geradas no acabamento.

QPA (un) = quantidade de peças acabadas.

APA $(\mathrm{kg})=$ quantidade média de aparas geradas no acabamento de uma única peça.

As quantidades de resíduos de papelão e plástico corresponderam exatamente às quantidades requisitadas do estoque, uma vez que todo o plástico e papelão requisitados, depois de contaminado com aparas, é descartado como resíduo. Esses dados, bem como os referentes aos resíduos Classe IIA dispostos em aterro, foram coletados junto aos arquivos do setor de Planejamento e Controle de Produção e Materiais da fábrica. Já os dados referentes às emissões de ruídos, poeiras e gases foram coletados a partir do Laudo Técnico de Condições Ambientais no Trabalho elaborado pela empresa estudada em parceria com o Serviço Nacional de Aprendizagem Industrial (SENAI). 


\section{RESULTADOS E DISCUSSÕES}

O processo de Moldagem e Acabamento em PRFV divide-se em duas grandes etapas: Moldagem e Acabamento (Figura 1).

Figura 1 - Fluxograma do processo de Moldagem e Acabamento em PRFV

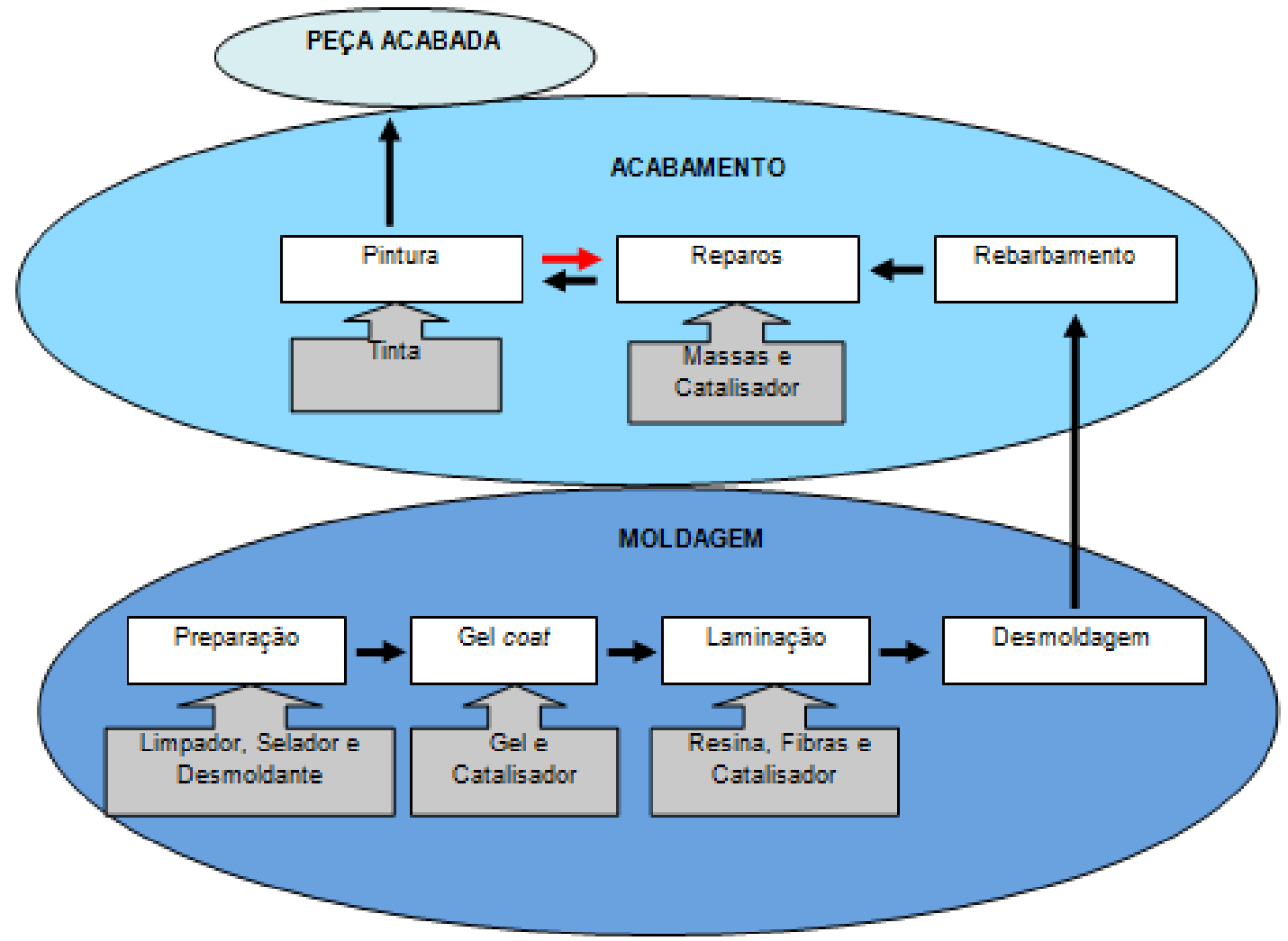

Fonte: Elaborado pelas autoras (2009)

A Moldagem inicia-se com a preparação dos moldes. Nos tetos, a parte final (não laminada) do molde é protegida com um plástico transparente. Em seguida, gel coat e catalisador são aplicados sobre a região a ser laminada com o uso de uma gelcoteadeira. Minutos depois, dá-se início à laminação, antes da qual todas as regiões sujeitas à impregnação com aparas são protegidas com papelão ondulado.

A laminação dos tetos inicia-se com a aplicação do fio moído (fibra de vidro moída). Em seguida, fio roving picado, resina e catalisador são atirados, simultaneamente, por uma pistola picadora contra a cavidade do molde com o uso de uma laminadora semi-automática. $O$ tecido e a manta de fibra de vidro são aplicados manualmente. Depois de aplicadas, as fibras são assentadas nos contornos do molde. Terminada a laminação, ocorre o rebarbamento, ou seja, a 
remoção das rebarbas nas duas laterais maiores dos tetos. Após a cura, ocorre a desmoldagem da peça.

Quanto à laminação das entre-janelas, a aplicação do fio roving inteiro e do fio moído ocorre de forma manual. Em seguida, essas fibras são umedecidas com resina e catalisador atirados por uma pistola. Posteriormente, aplica-se a manta e o tecido de fibra, que também são umedecidos com resina e catalisador; faz-se o assentamento das fibras e, imediatamente após a laminação, todas as rebarbas (laterais e vãos) são removidas. Após a cura, as entre-janelas são desmoldadas.

Uma vez desmoldados, conforme representado na Figura 1, tetos e entrejanelas seguem para o Acabamento. Nesta etapa, as rebarbas das duas laterais menores dos tetos são removidas e os pontos de corte são lixados. Em relação às entre-janelas, ocorre somente o lixamento, pois todas as rebarbas foram removidas antes da desmoldagem. Após o rebarbamento, as peças seguem para um processo de reparação de possíveis imperfeições. E por fim, são lixadas e conduzidas para uma pré-pintura.

$\mathrm{Na}$ unidade fabril estudada, a laminação das entre-janelas é totalmente manual (Figura 2). Já para laminar os tetos (Figura 3), a fábrica faz uso de uma tecnologia própria, na qual uma pistola picadora foi adaptada a uma máquina formando uma laminadora semi-automática, numa espécie de variação do spray-up. Os processos de laminação diagnosticados são similares aos apresentados por Matheus (2008). O referido autor descreve que na laminação manual (hand lay-up), as camadas de mantas e tecidos de fibras são posicionadas sobre o molde e impregnadas com resina e catalisador sem que haja o uso da laminadora. Já no spray-up, as fibras (roving picado), a resina e o catalisador são atirados, simultaneamente, sobre o molde por um equipamento (pistola air less). 
Figura 2 - Laminação manual de uma entre-janela

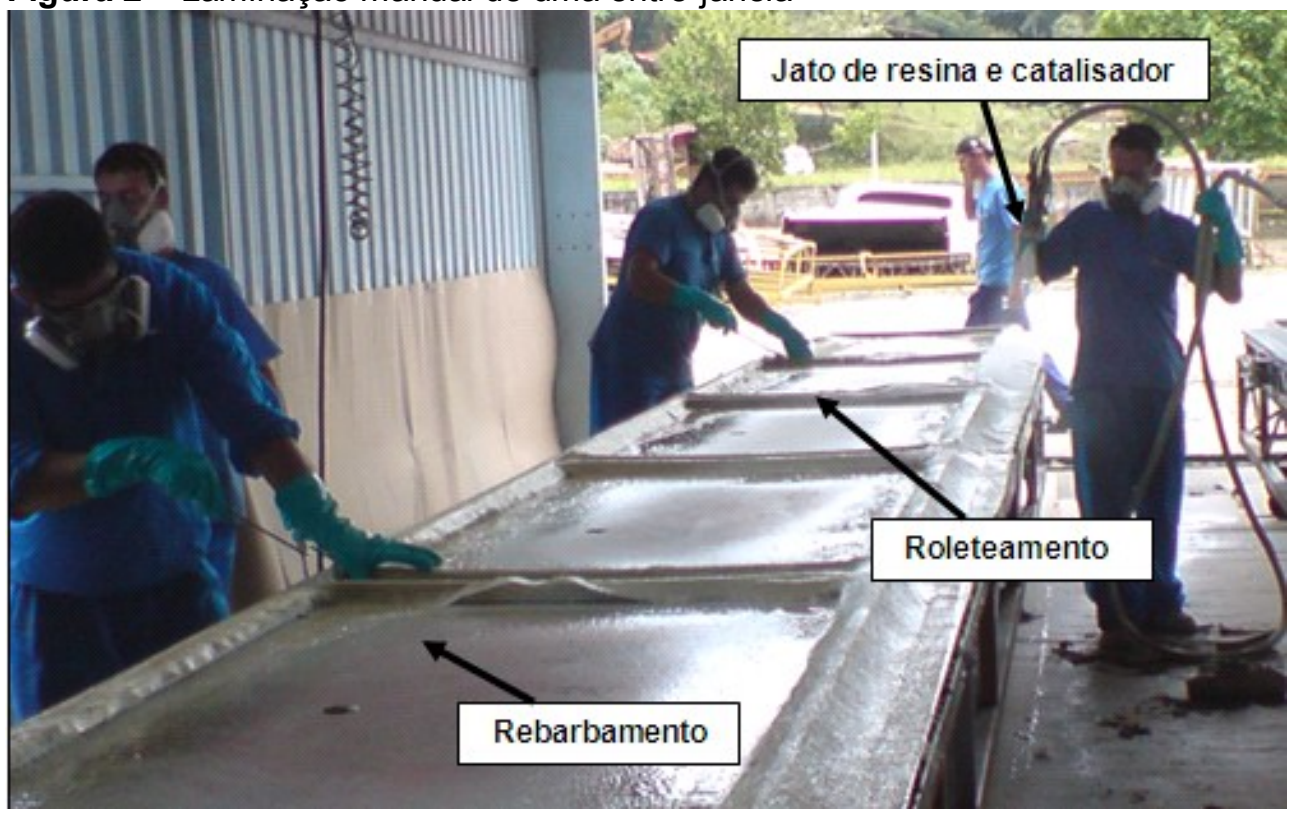

Fonte: arquivo das autoras (2009)

Figura 3 - Laminação de um teto com o uso de uma laminadora semi-automática

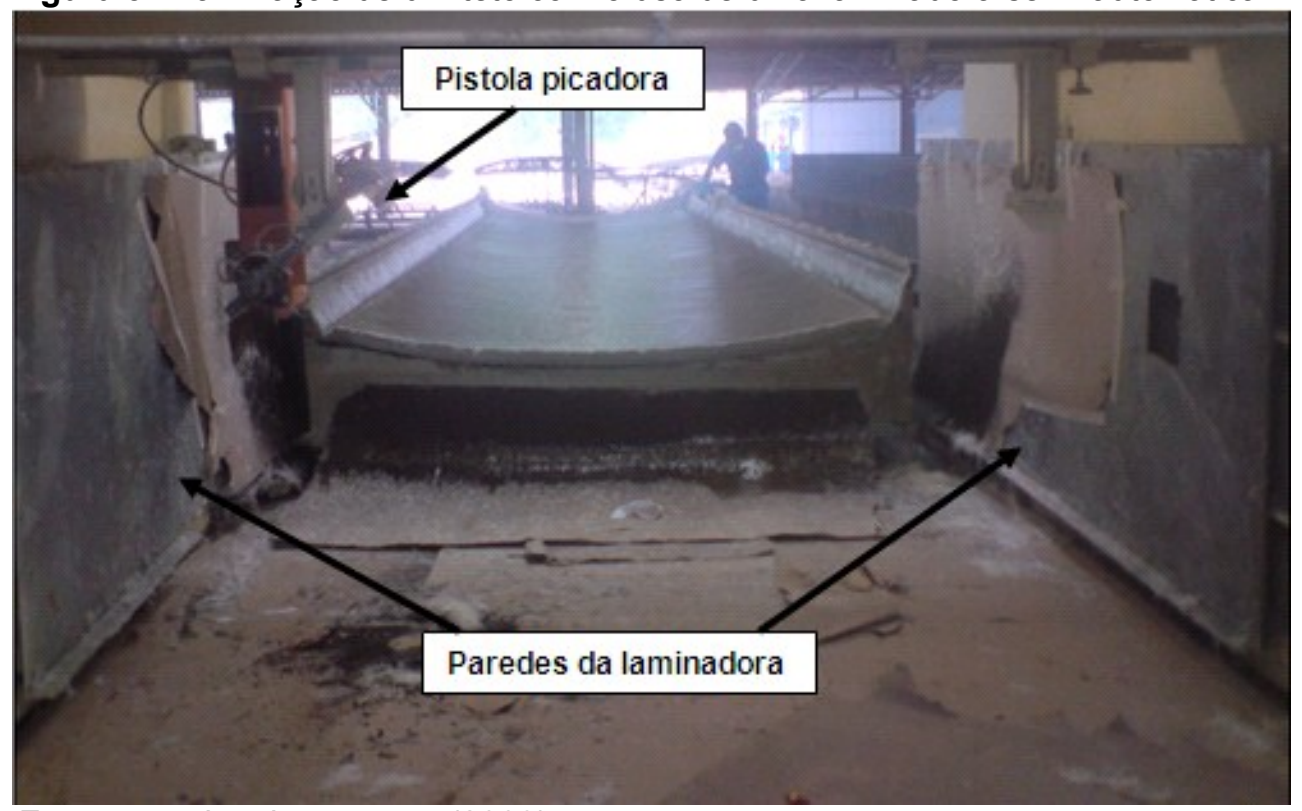

Fonte: arquivo das autoras (2009)

Outra constatação é que o processo de laminação (moldagem aberta) adotado pela fábrica, requer muita mão-de-obra, as peças produzidas são grandes e a variação no comprimento dos tetos pode chegar a centenas de tamanhos diferentes, embora a fábrica disponha apenas de oito moldes de tetos e quatro de entre-janelas. Tal fato só é possível devido à liberdade proporcionada pela moldagem aberta. Segundo Jacob (2002), todos esses fatores são característicos deste tipo de moldagem. 
A Tabela 1 apresenta um resumo do consumo médio mensal das matériasprimas usadas no processo produtivo estudado.

Tabela 1 - Consumo médio mensal das matérias-primas usadas no processo de Moldagem e Acabamento em PRFV no período estudado (maio de 2008 a abril de 2009)

\begin{tabular}{lc}
\hline \multicolumn{1}{c}{ Matéria-prima } & Consumo mensal médio (t) \\
\hline Resina para laminação & 44,18 \\
Talco industrial & 4,45 \\
Fibra de vidro (fio moído, fio roving, tecido e manta) & 16,90 \\
Gel coat cinza e fundo poliéster alta cobertura & 7,41 \\
Papelão ondulado e plástico polietileno transparente & 3,26 \\
\hline Total de matéria-prima & $\mathbf{7 6 , 2 0}$ \\
\hline
\end{tabular}

Observa-se que a unidade consome, mensalmente, mais de 75 toneladas de matéria-prima para laminar o que representa, em média, 358 peças. Segundo Milan e Grazziotin (2008), o elevado consumo de materiais é característico da moldagem aberta. O alto consumo de papelão e de plástico também se deve ao uso de moldes abertos, uma vez que esses materiais são usados para proteger regiões sujeitas à impregnação com aparas do processo (Figuras 4 e 5). Quando possível, o papelão é reutilizado (Figura 4a e 4c), porém, em alguns locais (Figuras $4 b$ e $4 d$ ), ele é trocado várias vezes durante a jornada de trabalho. Quanto ao plástico transparente, notese que a fábrica deu início a medidas que visam à redução ou eliminação do uso desse material (Figuras $5 b$ e $5 d$ ). 
Figura 4 - Uso de papelão na moldagem dos tetos e entre-janelas: a) piso e paredes - entrejanelas; b) piso e paredes da laminadora - tetos c) piso sob e em volta do molde do teto; d) frente do molde do teto

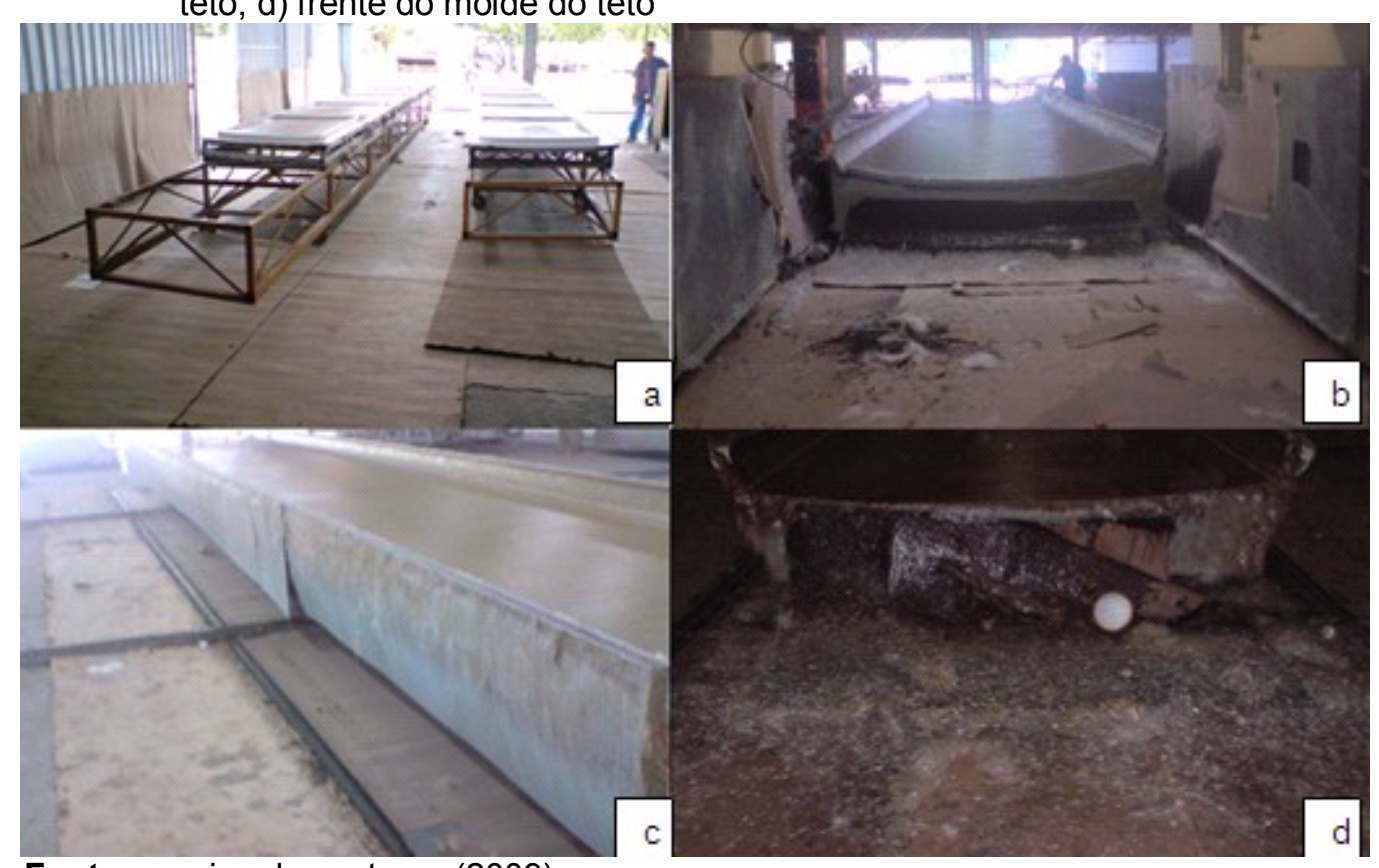

Fonte: arquivo das autoras (2009)

Figura 5 - Uso de plástico polietileno na moldagem dos tetos: a) proteção de partes não laminadas; b) anteparo usado para substituir o plástico; c) plástico cobrindo os moldes que não estão sendo utilizados; d) lona que passou a ser usada para cobrir os moldes

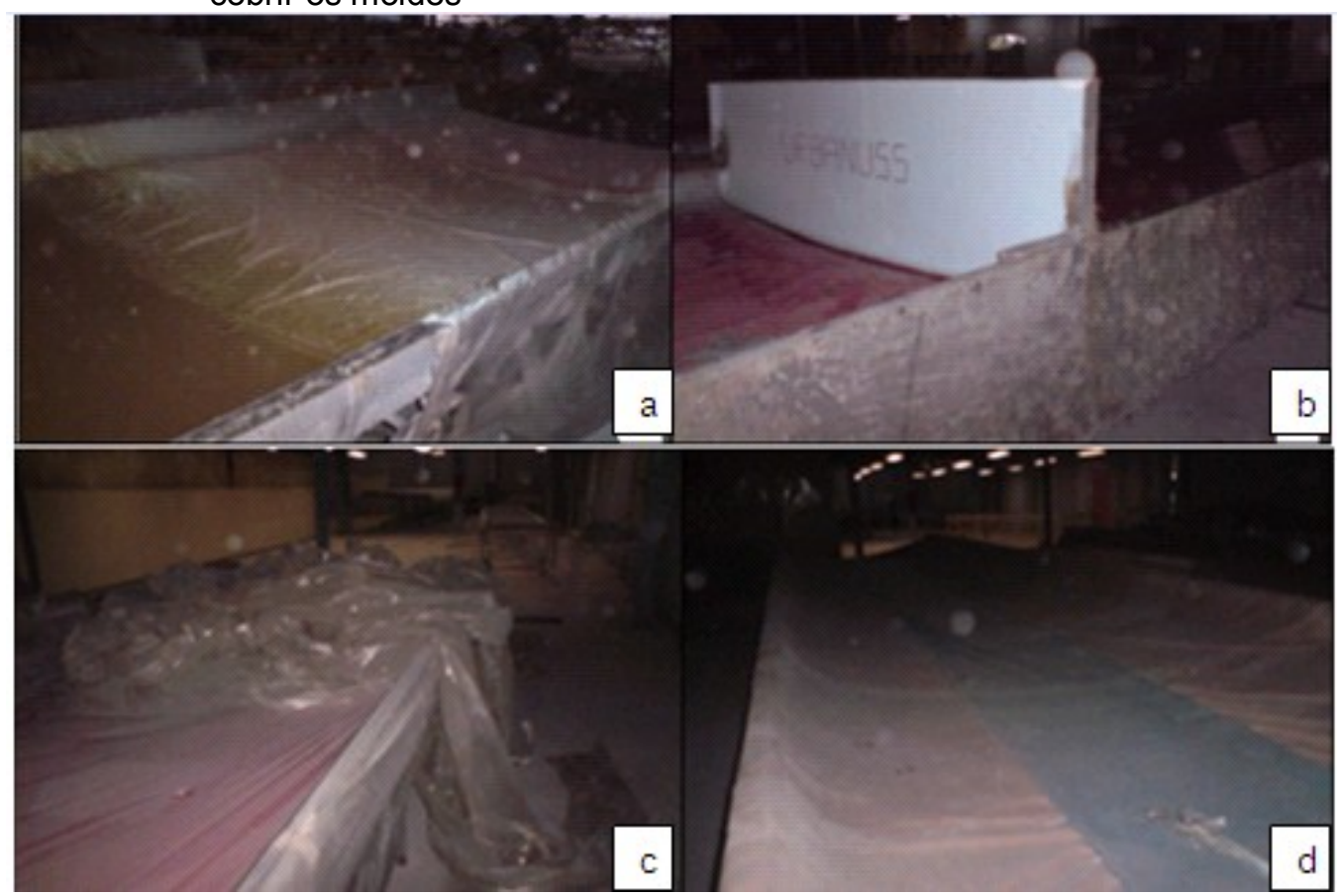

Fonte: arquivo das autoras (2009)

Na Figura 6, observa-se o grande volume de aparas de PRFV geradas em um mês de baixa de produção (abril de 2009). 
Figura 6 - Aparas do processo de Moldagem e Acabamento em PRFV geradas somente no mês de abril de 2009

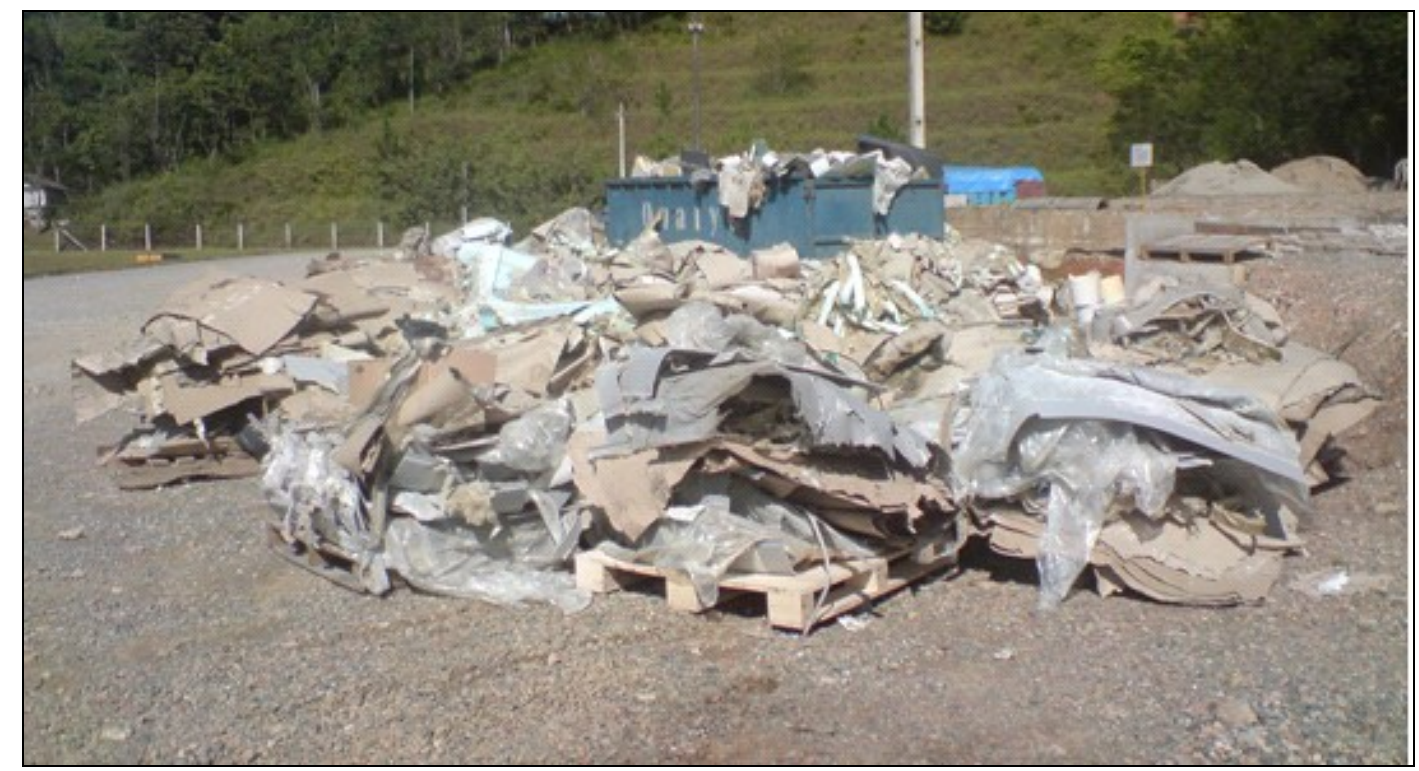

Fonte: arquivo das autoras (2009)

Para uma melhor compreensão da geração de resíduos no processo analisado, a Tabela 2 apresenta dados da produção mensal de peças em PRFV, da matéria-prima usada mensalmente para produzi-las, da quantidade de aparas livres de contaminação geradas a partir dessa produção e do percentual de perdas de matéria-prima. Percebe-se que em ambas as linhas de produção (tetos e entrejanelas), o consumo de matéria-prima e a perda de material foram significativos. Milan e Grazziotin (2008) explicitam que na moldagem aberta a geração de resíduos é elevada devido à formação de aparas laterais no molde e à perda de material decorrente de seu lançamento contra o piso, paredes e outros. Os referidos autores afirmam, ainda, que esta perda pode ser de $15 \%$ a $25 \%$, dependendo da geometria da peça. Sendo assim, na fabricação das entre-janelas, que são peças mais complexas, a perda de matéria-prima (30\%) é três vezes maior que na produção dos tetos (9\%). Embora a laminação dos tetos seja do tipo "spray-up", o uso de uma laminadora semi-automática aliado ao fato do teto ser uma peça extremamente simples explica o percentual de perda de $9 \%$, inferior ao mínimo de $15 \%$ descrito pelos autores aqui referenciados. 
Tabela 2 - Produção de peças em PRFV, matéria-prima usada para produzi-las, quantidade de aparas geradas e percentual de perda de matéria-prima na forma de aparas nas duas linhas de produção do processo de Moldagem e Acabamento em PRFV

\begin{tabular}{c|cccc|cccc}
\hline & \multicolumn{4}{|c}{ Tetos } & \multicolumn{4}{c}{ Entre-janelas } \\
$\begin{array}{c}\text { Mês I } \\
\text { Ano }\end{array}$ & $\begin{array}{c}\text { QPM } \\
\text { (un) }\end{array}$ & $\begin{array}{c}\text { MPU } \\
\text { (t) }\end{array}$ & $\begin{array}{c}\text { QAG } \\
\text { (t) }\end{array}$ & $\begin{array}{c}\text { PMP } \\
(\mathbf{\%})\end{array}$ & $\begin{array}{c}\text { QPM } \\
\text { (un) }\end{array}$ & $\begin{array}{c}\text { MPU } \\
\text { (t) }\end{array}$ & $\begin{array}{c}\text { QAG } \\
\text { (t) }\end{array}$ & $\begin{array}{c}\text { PMP } \\
\text { (\%) }\end{array}$ \\
\hline mai/08 & 382 & 75,32 & 7,05 & 9 & 29 & 0,8 & 0,24 & 30 \\
jun/08 & 386 & 76,95 & 7,21 & 9 & 121 & 3,32 & 1 & 30 \\
jul/08 & 494 & 99,8 & 8,95 & 9 & 82 & 2,25 & 0,68 & 30 \\
ago/08 & 375 & 74,72 & 6,94 & 9 & 64 & 1,76 & 0,53 & 30 \\
set/08 & 463 & 92,39 & 8,53 & 9 & 24 & 0,66 & 0,2 & 30 \\
out/08 & 352 & 70,41 & 6,43 & 9 & 63 & 1,73 & 0,52 & 30 \\
nov/08 & 259 & 52,5 & 4,82 & 9 & 34 & 0,93 & 0,28 & 30 \\
dez/08 & 310 & 63,17 & 5,82 & 9 & 23 & 0,63 & 0,19 & 30 \\
jan/09 & 281 & 56,72 & 5,21 & 9 & 13 & 0,36 & 0,11 & 30 \\
fev/09 & 157 & 32,18 & 2,94 & 9 & 4 & 0,11 & 0,03 & 30 \\
mar/09 & 149 & 30,55 & 2,71 & 9 & 31 & 0,85 & 0,26 & 30 \\
abr/09 & 185 & 36,81 & 3,42 & 9 & 12 & 0,33 & 0,1 & 30 \\
\hline Média & $\mathbf{3 1 6}$ & $\mathbf{6 3 , 4 6}$ & $\mathbf{6 , 0 5}$ & $\mathbf{9}$ & $\mathbf{4 2}$ & $\mathbf{1 , 1 4}$ & $\mathbf{0 , 3 4}$ & $\mathbf{3 0}$ \\
Mensal & & & & & & & & \\
\hline
\end{tabular}

Legenda: QPM - quantidade de peças moldadas; MPU - matéria-prima usada; QAG - quantidade de aparas geradas; PMP - percentual de perda de matéria-prima na forma de aparas.

A Tabela 3 apresenta dados da geração mensal (somatória) das aparas produzidas nas duas linhas de produção, o que inclui: as aparas livres de contaminação determinadas pelas Equações e todo o papelão e plástico requisitado do estoque e que foi contaminado após o uso, conforme descrito anteriormente.

Uma análise mais detalhada da Tabela 3 permite observar que entre maio e dezembro de 2008 , cerca de $45 \%$ de todos resíduos Classe IIA gerados pela fábrica correspondiam, somente, às aparas do processo de laminação em PRFV. A partir de novembro de 2008 , devido a problemas internos, houve uma redução na produção de autopeças e, consequentemente, na geração de resíduos. A partir de então, a coleta de resíduos passou a acontecer em função do acúmulo na área de armazenagem temporária da empresa. Assim, resíduos gerados em um determinado mês só seguiram para seus destinos finais um ou dois meses depois. Não fosse por esta razão, a situação constatada entre maio e dezembro de 2008 , onde $45 \%$ de todos os resíduos Classe IIA gerados pela fábrica eram aparas de PRFV, se repetiria nos meses finais do período analisado. Ainda assim, observa-se na Tabela 
3 que, mesmo com a queda na geração de resíduos, a fábrica dispôs em aterros 109,53 toneladas de aparas de PRFV no período de um ano.

Tabela 3 - Geração mensal de aparas de PRFV (aparas livres de contaminação + papelão e plástico contaminados) no processo de Moldagem e Acabamento em PRFV e de resíduos Classe IIA em toda a fábrica

\begin{tabular}{c|c|c|c}
\hline Mês/Ano & $\begin{array}{c}\text { Total de aparas do } \\
\text { processo PRFV } \\
(\mathbf{t})\end{array}$ & $\begin{array}{c}\text { Total de resíduos } \\
\text { Classe IIA da fábrica } \\
\text { (t) }\end{array}$ & $\begin{array}{c}\text { Percentual de } \\
\text { aparas de PRFV } \\
(\%)\end{array}$ \\
\hline mai/08 & 10,18 & 24,15 & 42 \\
jun/08 & 11,58 & 29,32 & 39 \\
jul/08 & 14,95 & 32,02 & 47 \\
ago/08 & 11,92 & 29,2 & 41 \\
set/08 & 13,86 & 26,29 & 53 \\
out/08 & 11,11 & 24,19 & 46 \\
nov/08 & 7,86 & 15,77 & 50 \\
dez/08 & 8,38 & 19,04 & 44 \\
jan/09 & 7,03 & 8,45 & $*$ \\
fev/09 & 4,07 & 6 & $*$ \\
mar/09 & 4,01 & 29 & $*$ \\
abr/09 & 4,58 & 2,7 & $*$ \\
\hline Total & 109,53 & 246,13 & $*$ \\
\hline
\end{tabular}

* Nestes meses a coleta de resíduos Classe IIA não seguiu o "cronograma", razão pela qual não foi possível proceder-se ao cálculo do percentual.

A geração excessiva de aparas de PRFV implica tanto em prejuízos ambientais quanto econômicos. O fato de serem resíduos extremamente volumosos aumenta os gastos da empresa com o transporte e potencializa os prejuízos ambientais relacionados a esse procedimento, dentre eles, a emissão de gases poluentes pelos veículos transportadores. Já a disposição desses resíduos em aterros, sem nenhum tratamento prévio que ao menos reduza o seu volume, além de elevar os custos de sua disposição, contribui para acelerar o fim da vida útil do aterro. Soma-se a isso, o fato das aparas não serem biodegradáveis por se constituírem, basicamente, de fibras de vidro e resinas termofixas. Em se tratando da reciclagem, o que poderia diminuir o volume a ser disposto, a unidade não adota nenhuma medida de reutilização ou reciclagem relacionada às aparas de processo, embora já exista tecnologia disponível para esse fim. Já a contaminação do papelão e do plástico, materiais comumente recicláveis, inviabiliza a sua reciclagem.

Revista Produção Online, Florianópolis, SC, v.12, n. 2, p. 537-556, abr./jun. 2012. 
É importante frisar, ainda, que a significativa perda de matéria-prima no processo analisado implica na aquisição de novos materiais, especialmente resinas e fibras de vidro, cujos processos de produção, transporte e estocagem também resultam em sérios impactos ambientais, dentre eles, a contribuição para o esgotamento dos recursos naturais necessários para a fabricação desses materiais

Considerando o que foi diagnosticado e o fato de que a redução de resíduos deve, preferencialmente, iniciar-se em sua fonte geradora, a unidade fabril estudada precisa considerar a possibilidade da adoção de tecnologias mais limpas e mais modernas e que gerem menos resíduos. Segundo Tocchetto (2005), a redução de resíduos na fonte geradora consiste numa medida preventiva e pode se dar, dentre outras ações, por meio de modificações no processo produtivo ou da adoção de novas tecnologias. Corroborando essa solução, Milan e Grazziotin (2008), ao realizarem a implantação da Produção mais Limpa em uma empresa do setor PRFV, concluíram que a moldagem aberta era a responsável pela grande geração de resíduos. Diante disto, propuseram, à empresa estudada por eles, a migração para um processo mais moderno, como o RTM light (moldes fechados). Segundo os autores, após a migração, a perda de material que antes era de $19,5 \%$ ao mês, sofreu uma queda de $80 \%$, passando a ser de apenas $4 \%$.

Considerando que a adoção de novas tecnologias pode implicar em altos investimentos, uma alternativa mais barata, para a unidade fabril estudada, seria a otimização do processo já adotado pela empresa. Jacob (2002) relata que o mercado dispõe de pistolas de spray-up mais eficientes e que além dos requisitos básicos, oferecem um padrão mais uniforme de pulverização, gerando menos resíduos. Além disso, há equipamentos como: monitores de fibra e resina; alarmes de catalisador; aquecedores de resina e outros que prometem aumentar a eficiência do processo.

Além dos riscos ambientais relatados, destaca-se que o uso de moldes abertos pode implicar, também, em sérios danos à saúde dos trabalhadores que lidam com este tipo de processo. Na fábrica estudada, a produção de ruídos e a emissão de vapores, gases e poeiras é constante, em diferentes intensidades e tem como fontes geradoras o uso de matérias-primas, insumos, máquinas e equipamentos. A Tabela 4 apresenta dados referentes a essas emissões nas duas grandes etapas em que o processo se divide. 
Tabela 4 - Avaliação quantitativa dos riscos físicos e químicos nas duas etapas do processo de Moldagem e Acabamento em PRFV da unidade estudada

\begin{tabular}{|c|c|c|c|}
\hline Riscos & Moldagem & Acabamento & $\begin{array}{l}\text { Limites de } \\
\text { Tolerância }\end{array}$ \\
\hline Ruído* & $85,3 \mathrm{~dB}(\mathrm{~A})$ & $90,7 \mathrm{~dB}(\mathrm{~A})$ & $85 \mathrm{~dB}(\mathrm{~A})$ \\
\hline Acetona** & $0,585 \mathrm{ppm}$ & $3,032 \mathrm{ppm}$ & 780 ppm \\
\hline Álcool Etílico** & $0,384 \mathrm{ppm}$ & - & 780 ppm \\
\hline Metil Etil Cetona** & $0,436 \mathrm{ppm}$ & - & 155 ppm \\
\hline Estireno (preparação e laminação) ${ }^{* *}$ & $104,721 \mathrm{ppm}$ & 29,378 ppm & 78 ppm \\
\hline Estireno (desmoldagem do teto) ${ }^{\star *}$ & 34,198 ppm & - & 78 ppm \\
\hline Poeira respirável & - & $4,51 \mathrm{mg} / \mathrm{m}^{3}$ & $3 \mathrm{mg} / \mathrm{m}^{3}$ \\
\hline
\end{tabular}

Considerando-se os dados apresentados na Tabela 4, observa-se que tanto a Moldagem quanto o Acabamento representam atividades prejudiciais aos trabalhadores segundo os riscos relacionados no anexo IV do Decreto 3.048 de 06.05.1999 do INSS item 2.0.1 (ruído). Entretanto, a insalubridade em grau médio devido à exposição habitual e permanente (8 horas diárias) acima de $85 \mathrm{~dB}(\mathrm{~A})$ limite de tolerância determinado no anexo 01 da NR 15 da Portaria 3.214 do Ministério do Trabalho - pode ser neutralizada com o uso de protetores auriculares (LTCAT, 2008). Note-se que todos os trabalhadores, visitantes, fornecedores, além de qualquer pessoa que circule pela fábrica são orientados a usar tais protetores.

$\mathrm{Na}$ Moldagem, o nível de estireno na preparação e laminação do molde é $34 \%$ superior ao limite tolerado (78 ppm), o que caracteriza essa atividade como prejudicial à saúde segundo os riscos relacionados no anexo IV do decreto 3.048 de 06.05.1999 do INSS item 1.0.191 (estireno). Ressalta-se que o local onde ocorre a preparação e a laminação é pouco ventilado e não possui exaustores, o que contribui para aumentar o nível de estireno em suspensão. Embora, como se lê em Makeni (2004), o ideal seja que produtos ou os seus derivados que liberem estireno sejam manuseados em locais ventilados e/ou com exaustores que conservem os níveis de partículas em suspensão abaixo dos limites de tolerância.

O uso de moldes abertos é o principal fator que contribui para elevar os índices de estireno na fábrica. O spray-up é considerado um processo "sujo" não só pela grande quantidade de aparas geradas, mas também pelas altas emissões de estireno. Diante desses riscos advindos do spray-up, a sociedade, os governos e o 
mercado têm pressionado os produtores de materiais compósitos, levando-os a exigirem de seus fornecedores - fabricantes de equipamentos de spray-up - o desenvolvimento de tecnologias que liberem menos estireno (JACOB, 2002).

É importante frisar que o estireno pode causar, dentre outros problemas, irritações nos olhos, pele e aparelho respiratório, além de náuseas, perda de apetite, depressão do Sistema Nervoso Central e debilidade geral. No entanto, conforme o LTCAT (2008), a insalubridade em grau médio devido à exposição ao estireno acima do limite de tolerância determinado no anexo $n^{\circ} 11$ da NR 15 da Portaria 3.214 do Ministério do Trabalho pode ser neutralizada com a utilização adequada de EPIs como: respiradores; luvas de borracha ou vinil; óculos de proteção para produtos químicos; roupa de proteção para minimizar o contato com a pele; mangas compridas; avental; botas e capacete de boa resistência (MAKENI, 2004). Com exceção do capacete, os trabalhadores da unidade estudada se protegem da exposição ao estireno fazendo uso de todos os demais EPIs citados.

No setor de Acabamento, a emissão do "pó de fibra" resultante do rebarbamento do compósito, também está acima do limite tolerado. O que é preocupante, uma vez que a exposição e inalação aguda desse "pó" podem causar irritações na pele, nos olhos ou no aparelho respiratório. Entretanto, estes riscos, a exemplo dos demais, podem ser neutralizados com o uso de EPIs: máscaras contra poeira; calças e camisas de mangas compridas; luvas; gorro; avental; óculos de segurança e protetor facial. É importante ressaltar que, na fábrica estudada, o rebarbamento dos compósitos é feito em presença de água, o que, segundo a Maxi Rubber (2009), ameniza os riscos relacionados à emissão dessas poeiras, uma vez que água evita a liberação de partículas no ar.

\section{CONSIDERAÇÕES FINAIS}

A moldagem aberta é o processo de produção de compósitos mais usado mundialmente. $\mathrm{O}$ uso de processos tradicionais, de baixa tecnologia e que requerem poucos investimentos e conhecimentos técnicos - caso da moldagem aberta - muitas vezes são decisivos na escolha do processo produtivo a ser adotado por determinadas empresas, não havendo qualquer preocupação com o meio ambiente ou com a saúde dos trabalhadores. Fato este, constatado na empresa estudada, onde se comprovou que o uso de moldes abertos para a laminação de compósitos Revista Produção Online, Florianópolis, SC, v.12, n. 2, p. 537-556, abr./jun. 2012. 
em PRFV é o principal responsável por perdas de matéria-prima e, consequentemente, pela intensa geração de resíduos (aparas de processo). Ambas as situações implicam tanto em prejuízos ambientais, quanto econômicos. Soma-se a isto o fato do uso de moldes abertos representar uma ameaça à saúde dos trabalhadores devido às altas emissões de estireno e de "pó de fibra".

Ressalta-se que situações como a diagnosticada nesta pesquisa (uso de tecnologias baratas, "sujas" e tradicionais) se repetem em outras indústrias, independentemente de sua atividade ou porte, o que leva os governos, o mercado e a sociedade a pressionarem tais empresas a tornarem seus processos produtivos menos agressivos. Sendo assim, empresas que queiram melhorar a sua imagem no mercado, atingir novos consumidores e atender às normas e legislações cada vez mais rígidas, precisam incorporar a questão ambiental e de saúde e segurança do trabalhador de forma mais efetiva em suas rotinas de trabalho. Neste sentido, não apenas a unidade estudada como também outras empresas que adotem processos "sujos", precisam buscar meios de reduzir os impactos negativos desses processos e, a principal solução, sem dúvidas, está na adoção de tecnologias mais limpas e mais modernas.

O uso de tecnologias modernas e menos agressivas na laminação de PRFV tem se revelado de extrema importância para o setor automobilístico. Destaca-se que existem montadoras fora do Brasil que não permitem mais a compra de peças laminadas com o uso de moldes abertos. No entanto, há que se considerar que, geralmente, a adoção de novas tecnologias requer altos investimentos. Embora existam diversos exemplos de empresas que conseguiram reduzir custos em decorrência da economia de água, energia, matéria-prima, tratamentos, transporte e disposição de resíduos e, assim, obtiveram os devidos retorno e lucros decorrentes do investimento ambiental, alguns empresários ainda pensam que investir em meio ambiente e saúde representa mais despesas e retorno financeiro tardio ou incerto. Felizmente, tal pensamento vem mudando. Inserir a questão ambiental e de saúde e segurança dos trabalhadores em suas rotinas tem sido, para muitas empresas, uma questão de sobrevivência, fato este que deve ser considerado pela empresa estudada.

Em situações como esta, de resistência empresarial à inovação, uma alternativa é promover medidas de reutilização, reciclagem, recuperação e tratamentos que visem à redução de resíduos sólidos, líquidos e gasosos, seja em Revista Produção Online, Florianópolis, SC, v.12, n. 2, p. 537-556, abr./jun. 2012. 
quantidade ou em potencial contaminante. Quanto à reciclagem, há situações em que resíduos gerados em processos produtivos, depois de reprocessados, tornamse matéria-prima para a própria indústria que o gerou. Outro encaminhamento a ser dado refere-se a elaboração de Planos de Gerenciamento de Resíduos que contemplem, além dos aspectos básicos, a redução na fonte geradora, a reutilização e a reciclagem.

Os resultados da pesquisa nos levaram a concluir que a empresa estudada precisa, o quanto antes, investir em tecnologias que tornem o seu processo de fabricação de compósitos em PRFV menos agressivo, tanto ao meio ambiente quanto à saúde de seus trabalhadores. O que foi constatado reforça a afirmação de que as indústrias devem, sempre, buscar por alternativas que reduzam os impactos negativos de seus processos. A redução de resíduos sejam eles, sólidos, líquidos ou gasosos, precisa fazer parte da política das empresas. Além disso, é de extrema importância que o processo de prevenção seja contínuo e melhorado a cada dia.

\section{REFERÊNCIAS}

BERTINATO, C. B. de. Dermatoses Ocupacionais em Indústria Automobilística. In: JORNADA PARANAENSE DE SAÚDE OCUPACIONAL, 22, 2007, Curitiba. Anais eletrônicos... Curitiba: APAMT, 2007. Disponível em:

<http://www.apamt.org.br/anais_2007/xxii_jornada-anais/temas_livres/tema5.pdf> Acesso em: 21 out. 2008.

CANTO, E. L. do. Plástico: bem supérfluo ou mal necessário. 4. ed. São Paulo: Moderna, 1997.

GARCIA, S. Referencias históricas y evolución de los plásticos. Revista Iberoamericana de Polímeros, v. 10, n.1, p. 71-80, 2009.

JACOB, A. Spray-up offers process improvements. Reinforced Plastics, v.46, n.1, p. 32-34, January, 2002, (artigo com tradução livre das autoras).

LIMA, Gilmar. Compósitos vislumbram oportunidades nas áreas de transporte e infra-estrutura. Revista Plástico Moderno, ed. 423, jan. 2010. Disponível em: <http://www.plastico.com.br/plastico.htm>. Acesso em: 11 mar. 2010.

LTCAT. Laudo técnico de condições ambientais no trabalho. Joinville: SENAI, 2008.

MAKENI Chemicals Comércio de Produtos Químicos LTDA. Ficha de informações de segurança de produtos químicos: monômero de estireno. São Paulo, 2004. Disponível em: <http://www.makeni.com.br> Acesso em: 27 ago. 2009. 
MATHEUS, M. A. Fiberglass: aprenda fibra de vidro. Ribeirão Preto: M. a: Matheus, 2002, $132 \mathrm{p}$.

MAXI RUBBER INDÚSTRIAS QUÍMICAS LTDA. Ficha de Informações de segurança de produto químico, 2001. Disponível em:

<http://www.maxirubber.com.br/fispq.asp> Acesso em: 26 ago. 2009.

MILAN, G. S.; GRAZZIOTIN, D. B. G. Implantação da produção mais limpa em uma empresa do setor plástico. In: ENCONTRO NACIONAL DE ENGENHARIA DE PRODUÇÃO, 28, 2008. Rio de Janeiro. Anais eletrônicos... Rio de Janeiro: ABEPRO-ENEGEP, 2008. Disponível em:

<http://www.abepro.org.br/enegep2008/resumo_pdf/enegep/TN_STO_077_542_106 09.pdf>. Acesso em: 22 jun. 2008.

PINTO, Kelly Nanci Carneiro. Reciclagem de resíduos de materiais compósitos de matriz polimérica: poliéster insaturado reforçado com fibras de vidro. São Paulo, 2002. Dissertação (Mestrado) - Universidade de São Paulo. São Paulo, 2002.

TOCCHETTO, M. R. L. Gerenciamento de resíduos sólidos industriais: curso de química industrial. Universidade Federal de Santa Maria.Santa Maria: UFSM, 2005, $97 \mathrm{p}$.

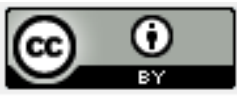

Artigo recebido em 24/02/2011 e aceito para publicação em 24/01/2012. 